Running head: Superstition and causal illusions

\title{
Superstition predicts perception of illusory control.
}

\author{
Oren Griffiths ${ }^{1}$, Noor Shehabi ${ }^{2}$, Robin A. Murphy ${ }^{3}$ \& Mike \\ E. Le Pelley²
}

1. School of Psychology, Flinders University, Australia

2. School of Psychology, UNSW Sydney, Australia

3. Department of Experimental Psychology, University of Oxford, UK

Word count (exc. figures/tables): 7212

${ }^{*}$ Requests for reprints should be addressed to Dr. Oren Griffiths, Flinders University, Bedford Park, SA, 5042, Australia. (e-mail: oren.griffiths@flinders.edu.au). 


\begin{abstract}
Superstitions are common, yet we have little understanding of the cognitive mechanisms that bring them about. The present study used a laboratory-based analogue for superstitious beliefs that involved people monitoring the relationship between undertaking an action (pressing a button) and an outcome occurring (a light illuminating). The task was arranged such that there was no objective contingency between pressing the button and the light illuminating - the light was just as likely to illuminate whether the button was pressed or not. Nevertheless, most people rated the causal relationship between the button-press and the light illuminating to be moderately positive, demonstrating an illusion of causality. The present study found that the magnitude of this illusion was predicted by people's level of endorsement of common superstitious beliefs (measured using a novel Superstitious Beliefs Questionnaire), but was not associated with mood variables or their self-rated locus of control. This observation is consistent with a more general individual difference or bias to overweight conjunctive events over disjunctive events during causal reasoning in those with a propensity for superstitious beliefs.
\end{abstract}

Keywords: Superstition, contingency, associative learning, paranormal beliefs 


\section{Introduction}

Whenever superstitious beliefs are measured, most people profess belief in at least some (Sobal \& Eamons, 1982; Irwin, 1993). Superstition appears to be a culturally universal phenomenon, but the exact form of superstitious beliefs varies across cultures (Garett $\&$ Fisher, 1926; Sica, Novara \& Sanavio, 2002 ; Banasal, Dixit, Waskel, Mahore, Mishra \& Rokde, 2015; Gregory, 1975). In Western culture, common superstitions involve belief in extrasensory perception, astrology, some forms of spirituality, alternative therapies and precognition. Such beliefs can be considered to be a form of magical thinking in that they assume implausible or incoherent causal relationships akin to magic (see Lindeman \& Aarnio, 2006; Keinan, 2002; Zusne \& Jones, 1989 for ontological discussions). Extreme forms of thinking of this kind have been linked with obsessive-compulsive disorder (Einstein \& Menzies, 2004) and delusions (Johns \& van Os, 2001; Peters, Joseph, \& Garety, 1999; Chapman \& Chapman, 1987).

Superstitious beliefs are irrational and often make reference to implausible causal relationships. For this reason, superstitions constitute an ongoing puzzle for cognitive researchers because people are generally sensitive to causality in their environment (e.g., Baker, Murphy \& Vallée-Tourangeau, 1996). While causality cannot be directly experienced (causation cannot be seen), its effects can be observed in the form of the contingencies that are experienced between candidate causes and effects. If a given cue (or action) is a possible cause of an outcome event, then that outcome will be contingent upon the cue (or action). Thus causality can be inferred from observational data by measuring if that outcome occurs more often in the presence of the cue, than in the absence of that cue. This notion is formalised as:

$$
\Delta P=P(\text { Outcome } \mid \text { Cue })-P \text { (Outcome|No Cue) } \ldots \text { (1) }
$$

$\Delta \mathrm{P}$ refers to the contingency between a cue and an outcome, and varies from 0 to 1 (for 
generative causes; Jenkins \& Ward, 1965).

People are generally sensitive to quite small variations in contingency (Shanks, 1985; Vallée-Tourangeau, Hollingsworth, \& Murphy, 1998; Wasserman et al., 1993), which in turn affect their judgments of causality (see Cheng, 1997 for a discussion). This sensitivity allows people to learn the causal fabric of their environments. Superstitious beliefs seem to demonstrate an important exception to this rule because they invoke causal relationships for which there is no observable contingency: the probability of the outcome is the same with or without the cue (or action). So how might people come to believe in causal relationships for which there is no evidence? Some have argued that superstitions are maintained by various psychosocial mechanisms, such as people's desire to maintain their self-esteem (Alloy, Abramson \& Kossman, 1985; Alloy \& Clements, 1992) or personal investment in the belief system (Russell \& Jones, 1980). However, such explanations are insufficient to account for circumstances when little is personally at stake (Wohl \& Enzel, 2009). It appears likely that a more fundamental, cognitive mechanism is involved.

\section{Superstitious learning}

Skinner (1948) offered a prominent account of the development of superstitious behaviours derived from his study of pigeons. Suppose that a pigeon receives food rewards at random, unpredictable intervals. Suppose further that the pigeon happens to produce an idiosyncratic behaviour (e.g., lifting its wing) at just the same moment that a reward is delivered. Skinner argued that this adventitious reinforcement will increase the likelihood that the pigeon will produce this behaviour in future; and this, in turn, will make it more likely that the pigeon happens to be lifting its wing when food is delivered in future. If occasions on which wing-lifting happens to be paired with reward (i.e., random conjunctions of action 
and outcome) have a greater impact on the pigeon's behaviour than intervening occasions on which wing-lifting is not paired with reward (disjunctions) then this could be sufficient to sustain a 'superstitious' behaviour of wing-lifting in this pigeon.

While the empirical data that Skinner provided as evidence for his account has since been questioned (e.g., Staddon, 1992), the general approach that he offered still constitutes a plausible model of superstitions. For example, consider a baseball player who coincidentally eats chicken the night before a big match. If his team then won the match, he may continue to eat chicken before future matches, and therefore be frequently (but imperfectly) reinforced for his continued pre-match chicken diet. If the impact of conjunctions (eat chicken, win game) is greater than that of disjunctions (eat chicken, lose game), then this partial reinforcement may be enough to motivate the behaviour and bring about (and maintain) belief in the causal power of chicken to influence baseball victories. This example is not hypothetical: Wade Boggs (Boston Red Sox, 1982-1992) ate chicken before every match in his career.

This tendency to see causal relationships where none exist has been shown in the laboratory on numerous occasions (see Matute, Yarritu \& Vadillo, 2011 for a review). In a typical task, people are given a button that they can press (the cue or action) and are shown a light that sometimes turns on (the outcome event). They are then asked to press the button several times and watch its effect on the light, and also to not press the button on some occasions and see whether the light illuminates on its own. Following this experience, participants rate to what degree pressing the button causes the light to turn on.

Under these circumstances, people will often give a modest positive rating for the causal efficacy of the button, even if there is actually zero contingency between pressing the button and the light illuminating (i.e., the light is just as likely to illuminate if the button is 
pressed as if it is not: Alloy \& Abramson, 1979; Matute, 1994, 1996; Pronin, Wegner,

McCarthy, \& Rodriguez, 2006). This has been termed an illusion of causality (Matute et al, 2011), as people perceive a causal relationship where none exists.

The strength of this illusion is affected by a number of task-related factors. For example, the illusion is stronger when the outcome event is frequent (the outcome density effect, e.g. Allans \& Jenkins, 1980), when the outcome is desired or people are instructed to obtain it (Langer, 1975; Matute, 1994, 1995), when people are thinking about the outcome at the time it occurs (Pronin et al., 2006), when people make a lot of button presses (Matute, 1996) or when the time between button presses is long (Msetfi et al.., 2007). These studies cumulatively give some insight into the mechanisms by which the average person may be seduced by the apparent (but superstitious) contingency of their actions sometimes eliciting an outcome. Indeed, some have suggested that superstitions may be an inevitable (or even desirable) by-product of adaptive learning strategies (Beck \& Forstmeier, 2005; Damsich, Stoberock \& Mussweiler, 2010).

\section{Superstition and individual differences}

However, this body of research does not speak to differences between individuals in their propensity for superstitious beliefs. Consequently, a foundational assumption of this literature has largely gone untested. That is, it remains unclear that performance on laboratory studies of this kind is related to the superstitious beliefs that people hold in their everyday lives. This is important because people are not equally superstitious. Irwin (1993) reviewed the literature examining whether a propensity for paranormal beliefs (which included superstitions) was associated with culture, education, age or other demographic variables. Overall, there was variation in the degree to which people held these beliefs, such 
that paranormal beliefs were stronger in young people and women, with mixed evidence pertaining to the effects of socio-economic status, ethnicity or education.

While several studies have indirectly assessed whether superstitious beliefs are related to a propensity to experience illusions of causality (Brugger \& Graves, 1997; Van Elk, 2013; Musch \& Ehrenberg, 2002; Blackmore \& Troscianko, 1985), only one study has directly assessed this question (Blanco, Barberia \& Matute, 2015). In this study, Blanco et al. asked participants to determine whether a fictitious new medicine was effective or not. They were shown 40 fictitious patients, and were able to either administer the medicine, or not, for each patient, and then observed the consequences of that action (whether the patient's symptoms improved or not). Crucially, in one condition the medicine was programmed to be ineffective (i.e., had zero contingency with patient improvement). In this condition, the participants who reported the highest levels of paranormal beliefs gave higher ratings of the efficacy of the ineffective medication; that is, the more superstitious participants were more susceptible to illusory causation.

However, there is an important caveat to this finding. All participants were freely able to administer the medication to as many of the patients as they desired (e.g., for 2 out of 40 patients, or for 36 out of 40 patients), and those who were superstitious administered the medication more often than those who were not. In fact, once the frequency of actions (administering medication) was statistically equated between individuals, the relationship between superstition and contingency judgment was removed. This suggests that highly superstitious people behaved differently (i.e., they pressed the button more frequently), but that once this difference in behaviour was accounted for, there were no differences in their interpretation of the actual contingency information - the patterns of causes and effects. This hypothesis is supported by the observation that merely seeing the cause occur more 
frequently has been shown to be sufficient to increase people's ratings of perceived causation, regardless of their superstitious beliefs (the cue density effect; Vadillo, Musca, Blanco \& Matute, 2010).

Thus, while Blanco et al's (2015) study shows that superstitious people behave differently when testing their ideas, it stopped short of directly assessing any differences that originate in the perception of causation; that is, when holding the environmental information constant, will superstitious people see more causation in a zero-contingency arrangement than non-superstitious people? Experiment 1 tested this idea.

\section{Experiment 1}

Experiment 1 investigated whether degree of superstitious thinking was related to people's susceptibility to a causal illusion. Participants' degree of superstition was measured using a novel survey of commonly held superstitious beliefs (Experiment 2 further investigates the validity and reliability of this novel measure). Susceptibility to causal illusion was measured using a task in which participants were exposed to a zero-contingency relationship between pressing a button and a light illuminating, before being asked to judge the effectiveness of the button in causing the light to illuminate. Specifically, during the training phase participants experienced 40 trials on which they could either press, or not press, the button, and observed whether or not the lightbulb illuminated. Importantly, participants were explicitly instructed that they ought to press the button on approximately half of trials and refrain from pressing on the other half, so that they could judge the effectiveness of the button in making the light illuminate. To anticipate, participants generally followed this instruction - overall probability of acting was similar across levels of superstition, and this allowed us to assess the relationship between causal judgments and 
superstition independently of baseline differences in action-density. In particular, this procedure allowed for a sensitive test of whether differences in superstition are associated with differences in the conclusions that are drawn from similar (experienced) information. That is, this study investigated whether superstition is related to a general bias in information-processing wherein conjunctions (experiences of actions followed by outcomes) are overweighted relative to disjunctions (experiences of actions that are not followed by outcomes, or outcomes that are not preceded by actions).

A secondary set of hypotheses concerned the possible role of mood on perceptions of the zero-correlation contingency. It has previously been found that people who are depressed tend to not perceive causation when exposed to a zero contingency (Alloy $\&$ Abramson, 1979; Msetfi et al, 2007), which renders their judgments more accurate than nondepressed samples; often referred to as a "depressive realism" effect. This effect was thought to be driven by learned helplessness (Maier \& Seligman, 1976) or by cognitive defences to protect self-esteem (Alloy \& Abramson, 1982) such that depressed people hold lower a priori estimates of their capacity to control their environment (often referred to as an external locus of control; Rotter, 1975). To address these possibilities, measures of state depressive symptoms and locus of control were included in the current study. Finally, half of the participants were given a contingency task in which the outcome stimulus (the bulb illuminating) was rewarded, and half were not given any reward when the outcome occurred. This manipulation was included to assess any influence reward may have on the relationship between locus of control and causal judgments, as it has been argued that reward might moderate this relationship (Alloy \& Abramson, 1982). Jumping ahead, however, in the current study locus of control did not significantly predict causal judgments either in the overall sample or in either the rewarded or non-rewarded sub-groups considered in 
isolation; neither did the reward manipulation significantly impact upon the predictive capacity of superstitious beliefs (see Results section for details). For this reason, the manipulation of reward is not discussed further.

\section{Method}

Participants and apparatus. One hundred and sixty undergraduate students (mean age $=19.0,102$ were female) participated in exchange for course credit. Of these, 78 were assigned to the unrewarded condition, and 82 to the rewarded condition. The causal judgment task and all questionnaires were presented using Microsoft Visual Basic 6.0. All procedures were approved by the UNSW Human Research Ethics Advisory Panel (Psychology).

\section{Materials.}

Causal judgment task. The causal judgment task was based on that used by Msefti et al (2007). Participants' task was to learn how much control pressing a button had over the illumination of a light bulb. Full instructions are included in Appendix A. Importantly, as noted earlier, these instructions explicitly advised participants that they ought to press the button on half of trials, and refrain from pressing on remaining trials. This allowed participants to learn about what happened when they did not press the button. Participants in the rewarded condition were told that they would earn 10 points every time the light turned on, and that the four participants who earned the most points would each win two movie tickets.

Following these instructions, participants completed forty training trials. Each trial began with an image of an unlit light bulb, and an onscreen button that participants could click on if they chose (see Figure 1a). The onscreen button remained for $3 \mathrm{~s}$, and then was 
replaced by a statement reading either "BUTTON PRESSED" or "BUTTON NOT PRESSED," depending upon whether the button had been clicked during the preceding 3 s period. Simultaneously with this statement appearing, the lightbulb would then either illuminate, or remain unlit for $2 \mathrm{~s}$. The screen then cleared and the next trial began after an inter-trial interval of 3s. For participants in the rewarded condition, whenever the light turned on, the message "Win 10 points!" appeared just above the light bulb; when the light did not turn on, "No points" appeared.

Outcomes were scheduled such that the light illuminated on approximately $60 \%$ of the trials, regardless of whether the button was pressed or not (see Figure 1b). Specifically, a pool of twenty outcomes (12 with the bulb lit, 8 with it unlit) was created in advance for trials on which participants would choose to press the button, and an identical pool of outcomes was created for trials on which they would not press. On each training trial, the outcome (bulb lit or unlit) was sampled randomly without replacement from whichever of the pools applied (pressed or not pressed). This meant that if participants pressed the button on 20 of 40 trials, the light would illuminate on exactly $60 \%$ of the trials, and there was zero contingency between pressing the button and the light illuminating. Once all outcomes in a pool were exhausted (e.g., if a participant pressed more than 20 times, for all presses after the $20^{\text {th }}$ ) the outcome on each trial was generated independently with a probability of .6 of the light illuminating. This meant that the actual contingency between pressing the button and the light illuminating experienced by each individual could vary slightly around zero, depending on the number of times they chose to press (this is explicitly addressed in the Results section).

After forty trials, participants were asked to judge how much control pressing the button had over whether the light came on, by adjusting a slider on a scale from 0 (no 
control) to 100 (total control).

Superstitious Beliefs Questionnaire. We developed a novel, 25-item questionnaire to assess participants' levels of beliefs in common superstitions. A novel measure was constructed because previous measures (e.g., Tobacyk, 2004; Thalbourne \& Delin, 1993) contained statements that have not yet or cannot be verified, but which may be rational beliefs ("There is life on other planets") or items that have little bearing on daily life ("The abominable snowman of Tibet exists"). Instead, the items on the present scale were chosen to reflect beliefs held in the community, which address implausible causal relationships, and for which evidence (either for or against the belief) is likely to be encountered in ordinary life. For example, item 7 is: "There are things that we can do to improve our luck (e.g., carrying a lucky charm or choosing our lucky number in a random draw)." All instructions and items for this Superstitious Beliefs Questionnaire (SBQ) are listed in Appendix B. The questionnaire included a preamble relating to recent evidence for psi phenomena, ${ }^{1}$ so as to suggest a nonjudgmental atmosphere and hence encourage participants to report honestly on any superstitions that they might hold (without fear that they would be seen as irrational).

Participants rated the extent to which they agreed with each of the 25 statements, by clicking on the appropriate button given a choice of: Strongly disagree (scored as 0), Disagree (1), Neither agree nor disagree (2), Agree (3), or Strongly agree (4). Consequently, total scores could range from 0 to 100 , with higher scores indicating a greater degree of superstitious belief.

\footnotetext{
1 Which, incidentally, has now been largely discredited (see Galak, Leboeuf \& Nelson, 2012).
} 
Other questionnaire measures. Participants completed two further questionnaires. The 21 -item version of the Depression Anxiety Stress Scale (DASS; Lovibond \& Lovibond, 1995) was used to measure mood. The DASS has three sub-scales that index symptoms associated with depression, anxiety and stress. The Internal/External Locus of Control Scale (IE-LOC; Rotter, 1966), assessed participants' general beliefs about their capacity to control events in their environment. A high score on this measure indicates that a person believes they have more control over events (an internal locus of control), whereas lower scores indicate less perceived control (an external locus of control).

Procedure. After providing written consent, participants completed the causal judgment task, followed by the DASS, SBQ and IE-LOC questionnaires (in that order). The questionnaires were administered after the causal judgment task in order to exclude the possibility that their content (e.g., superstitious beliefs) would colour participants' view of the judgment task.

\section{Results}

Raw data from all experiments reported in this article are available via the Open Science Framework at https://osf.io/25maf/. All statistics were calculated using IBM SPSS (Version 24.0.0.2) and JASP (0.8.1.2), with the Type I error rate controlled at .05. Pearson correlations were used to quantify relationships between measured variables, and Bayes Factors $(B F)$ were calculated according to Bayesian null-hypothesis testing methods using JASP's default Cauchy prior with width 0.707 (JASP, 2017; see Marsman \& Wagenmakers, 2017 for details). Bayes Factors allow us to quantify the strength of evidence for the null hypothesis versus the alternative hypothesis. All Bayes Factors reported here represent $B F_{10}$; that is, a $B F$ of 1 indicates equal support for the null hypothesis and the alternative; a $B F$ less 
than 1 indicates greater support for the null; and a $B F$ greater than 1 indicates greater support for the alternative.

Causal judgment task. On average people pressed the button on approximately half of the trials $(M=55.5 \%, S D=13.2 \%)$. The experienced contingency $(\Delta P)$ between buttonpressing and light illumination was calculated for each individual (using Equation 1). Across participants, this experienced contingency closely approximated the intended contingency of zero $(M=0.00, S D=0.10)$. That said, as a consequence of the stochastic generation of outcomes for those who did not press on exactly half of trials, a small number of participants experienced a contingency that was somewhat further from zero. To mitigate against the impact of experience of outlying contingencies, the data of the 7 respondents who experienced a contingency greater than 0.2 or less than -0.2 were excluded from subsequent analyses (though excluding these participants had no effect on the pattern of significant and nonsignificant results in Experiment 1). For remaining participants, experienced contingency was very close to zero $(M=0.00, S D=0.06)$. There was no correlation between experienced contingency $(\Delta P)$ and participants' causal judgment ratings, $r(152)=.01, p=.92, B F=0.10$, presumably because there was little variance in experienced contingency across participants. There was also no significant correlation between causal ratings and proportion of buttonpresses, $r(152)=.09, p=.29, B F=0.17$.

Table 1 shows demographic information and summary data for the various components of the study for participants in the unrewarded and rewarded conditions. The only significant difference between these conditions was in participants' judgments of the strength of the causal relationship between pressing the button and the light illuminating. Averaged across all participants a causal illusion was present; the mean causal judgment 
rating $(M=35.4, S D=25.5)$ was significantly larger than zero, $t(152)=17.2, p<.001, d=$ $1.39, B F>1000$. However, those in the rewarded condition tended to give higher ratings $(M=40.3, S D=25.8)$ than those in the unrewarded condition $(M=30.1, S D=24.3), t(151)=$ $2.52, p=.01, d=0.41, B F=3.10$.

Questionnaires. Scores on each index of the three questionnaires (SBQ, DASS and IELOC) are summarized in Table 1. The novel SBQ measure of superstitious beliefs showed encouraging psychometric properties. The scale produced a wide range of scores $(0-85$, out of 100); Figure 2a shows the distribution of scores. Overall, the scale had high reliability, Cronbach's $\alpha=.90$ (Cronbach, 1951), and there was no indication that this depended on any one item (minimum $\alpha$ with any single item deletion $=.895$ ). Experiment 2 further assesses the reliability and validity of the SBQ measure.

SBQ score did not significantly correlate with any of the subscales of the DASS (see Table 2). However, there was a significant correlation between scores on the SBQ and the IELOC scale, $r(151)=-.25, p=.002, B F=12.2$, whereby higher superstition scores were associated with a more external locus of control (less perceived control of the environment).

Individual differences in causal judgments. The primary hypothesis concerned whether highly superstitious people were more likely to (incorrectly) perceive stronger causality between button-pressing and the light illuminating, as revealed in causal judgment ratings. The hypothesis was confirmed: Table 2 shows that SBQ scores were significantly correlated with causal judgment ratings, $r(151)=.22, p=.005, B F=4.76$. The relationship between superstition and causality ratings was similar (and significant) in both the rewarded group, $r(77)=.25, p=.028, B F=1.52$, and the unrewarded group, $r(72)=.24, p=.036, B F=$ 1.26 (see Figure 2b). The strength of the relationship between superstition and causal 
judgment appeared to differ between genders, being significant among females, $r(95)=.32$, $p=.002, B F=16.6$, but not among males, $r(54)=.10, p=.45, B F=0.22$.

Table 2 shows that, overall, causal judgments were not significantly correlated with scores on any of the subscales of the DASS, or with the IE-LOC, smallest $p=.24$, largest $B F=$ .20. The Bayes Factors for these correlations provide moderate support for causal judgments being independent of these predictors. Separate analyses for the rewarded and unrewarded conditions found a nonsignificant trend towards a negative correlation between causal judgments and DASS depression for the rewarded group, $r(77)=-.21, p=.06, B F=0.80$, with the Bayes Factor suggesting the data are equivocal in this case. All other correlations were nonsignificant, smallest $p=.14$, largest $B F=0.42$. IE-LOC was not significantly correlated with causal judgments in the rewarded or non-rewarded groups, smallest $p=.20$, largest $B F$ $=0.31$.

Notably, analysis of partial correlations revealed that the relationship between causal judgments and SBQ scores remained significant when controlling for scores on all other questionnaire measures, $r(147)=.21, p=.012$, or when controlling for differences in experienced contingency $(\Delta P)$ and proportion of trials on which participants chose to press the button, $r(149)=.23, p=.005$. Results of these analyses suggest a reliable and specific relationship between SBQ scores and causal judgments.

However, correlations may not be the most appropriate way to test the primary hypothesis, because any rating of causality that is greater than zero is essentially illusory (since the programmed contingency was zero, and the experienced contingencies closely approximated this value). The size or degree of this illusion may be of secondary importance relative to its mere presence; it is the belief in a causal property (e.g., luck), not the magnitude of its effect (e.g., how "lucky" a charm is), that defines a belief as superstitious. 
Instead superstition may be better indexed by people's propensity to give a non-zero causality rating (i.e., to perceive an illusory button-light relationship), rather than the size of that perceived causal relationship (i.e., their rating of the contingency).

Accordingly, we assigned participants giving causal judgment ratings of less than 10 (out of 100) to a 'correct' group ( $n=36)$, and participants giving higher ratings to an 'incorrect' group ( $n=117)$, collapsing across rewarded and unrewarded conditions. Figure 2c shows SBQ scores of the resulting groups; a paired t-test revealed that the correct group had significantly lower superstition scores than the incorrect group, $t(151)=4.36, p<.001, d=$ $0.83, B F=780.5$.

\section{Experiment 2}

We postpone discussion of the findings of Experiment 1, to first consider further the psychometric properties of the SBQ measure of superstitious beliefs. Given that this was a novel survey instrument, it is important to establish its validity and reliability. This was the aim of Experiment 2.

\section{Method}

Participants and procedure. Experiment 2 was run online. A total of 253 participants (Table 3 shows demographic data; participation was open to US residents only) were recruited via Amazon Mechanical Turk, and were paid 1 USD for completing the first session. Two weeks later, all participants were contacted and invited to complete the second session for a further payment of 1.50 USD; 199 participants completed this second session (mean time between sessions was 14.6 days, $S D=1.34)$.

In each session, participants completed the SBQ scale and two other measures of superstition that have been used in previous research: the Revised Paranormal Beliefs Scale 
(PBS, 26 items; Tobacyk, 2004), and the Australian Sheep-Goat Scale (AS-GS, 18 items;

Thalbourne \& Delin, 1993). Participants completed these three questionnaires in random order. Questionnaire items were presented individually and participants responded by selecting the appropriate option with the mouse. Stimulus presentation was controlled using the jsPsych Javascript library (de Leeuw, 2015).

\section{Results}

Table 3 summarizes scores on the three questionnaires for each session. Calculating Pearson correlations revealed that scores on the different measures were highly correlated in Session $1(N=253):$ SBQ and PBS, $r=.88 ;$ SBQ and AS-GS, $r=.81$; PBS and AS-GS, $r=.83$; all $p \mathrm{~s}<$ $.001, B F s>1000$. Such strong correlations between the SBQ and the PBS/AS-GS indicate good convergent validity with other commonly used measures of superstitions. Test-retest reliability of all three scales was assessed by correlating the test scores in Session 1 with scores in Session 2 for the 199 individuals who completed both sessions. Correlations for all measures exceeded .90, indicating good test-retest reliability: SBQ, $r=0.93$; PBS, $r=.94$; AS$\mathrm{GS}, r=0.91 ;$ all $p \mathrm{~s}<.001, B F \mathrm{~s}>1000$.

As for the lab-based Experiment 1, the internal consistency of item scores for the SBQ was high in this online sample, Cronbach's $\alpha=.95$ for Session 1 data. To explore the potential factor structure of the SBQ scale, an exploratory principal components analysis (PCA) was conducted using the responses to each item in Session 1. The suitability of these data for factor analysis was assessed by inspecting the item-by-item correlation matrix, with many correlations exceeding 0.3 . The Kaiser-Meyer-Olkin value was 0.95 , exceeding the recommended value of 0.6 (Kaiser, 1974) and Bartlett's test of sphericity (Bartlett, 1954) reached significance $\left(\chi^{2} 300=4392.80 p<.001\right)$. PCA revealed three components with 
eigenvalues exceeding 1.0 , which explained $48.45 \%, 7.55 \%$, and $5.48 \%$ of the variance, respectively. Using Catell's (1966) scree test a clear elbow was observed after the first component. A parallel analysis was performed using Watkin's (2005) tool (25 items $\times 253$ participants $\times 1000$ replications). The maximum eigenvalue was 1.62 (then 1.52), which exceeded all but two of the components observed in the initial PCA. Inspection of the component matrix showed that all 25 items of the SBQ loaded on component \#1 with coefficients ranging from .83 to .38 . Moreover, every individual item loaded more heavily on component \#1 than on component \#2 (for those few that loaded on component \#2 at all). Cumulatively, this pattern suggests a single-factor solution was the most appropriate, given (1) the dominance of component \#1 in the scree plot, (2) the concentration of coefficients on component \#1 and, (3) the low eigenvalue and variance explained by the additional components. In summary, these data suggest that the SBQ provides a valid and reliable measure of a single property: in effect a 'general superstition level'.

\section{General discussion}

Returning to the findings of Experiment 1, we found that people's degree of superstition (assessed using a novel measure, the SBQ) predicted whether they perceived a zero-contingency relationship as causal. Participants reporting high levels of superstitious beliefs tended to rate the button-press as having caused the light to illuminate-a causal illusion-whereas those with low superstition were less susceptible to this illusion, and tended to (correctly) see the events as unrelated. This relationship was independent of any small differences between people in the frequency of button-pressing or in the exact presslight contingency that they observed. The relationship held both for the magnitude of people's causal judgments (i.e., the degree of causality people saw the button press as 
possessing), and also the propensity to infer causation (i.e., whether people saw a causal relationship between the two events, irrespective of its magnitude). While the magnitude of this relationship was (numerically) relatively small, it appears robust: Bayesian analyses showed that it was 6 times more likely that the magnitude of causal judgment ratings was associated with SBQ score, than that the two variables were independent; moreover, it was 839 times more likely that susceptibility to a causal illusion was associated with higher SBQ scores than that it was not. Interestingly, the evidence for this illusion was concentrated in female participants: there was a significant relationship between the causal illusion and superstition scores in females, but no significant relationship in males. It was not the intention of this experiment to investigate gender differences, so the findings of this gender analysis should be treated as exploratory and are not pursued further here. Nevertheless we note that this finding is broadly consistent with others that have documented gender differences in rates of endorsement of superstitious beliefs (Aarnio \& Lindeman, 2005). With respect to mood and locus of control, neither predicted causal ratings; in particular, no evidence of a depressive realism effect was observed (see also Allan, Siegel, \& Hannah, 2007).

The present data make an important additional contribution to the superstition literature by examining the operation of basic causal learning mechanisms that are often assumed to be related to superstitions (see Yarritu, Matute \& Luque, 2015; Blanco et al, 2015). While numerous studies have examined whether particular groups of people are more or less likely to endorse superstitious beliefs (see Irwin, 1993 for a review), or have investigated general cognitive factors or deficits thought to be related to superstitious thinking (for reviews see French, 1992; Wiseman \& Watt, 2006), there has been relatively little work examining the basic cognitive mechanisms by which people might arrive at 
superstitious or paranormal beliefs, and whether these cognitive mechanisms differ across individuals. Our data suggest that higher levels of superstition are associated with a general bias to perceive a causal relationship where none exists, even between arbitrary events that are not related to the specific content of the superstitious beliefs that an individual holds.

The current findings complement recent research by Blanco et al. (2015). As noted in the Introduction, they found that when superstitious people were asked to test a causal relationship (the effect of a new medicine), they more frequently intervened in the system (gave the patient the medicine) than did less superstitious people. Overall Blanco et al. found that more superstitious people also showed a greater illusion of control than less superstitious people; that is, more superstitious people were more likely to rate an objectively noncontingent relationship as causal. This finding is consistent with the present study. However, Blanco et al. found that the association between superstition and causal ratings depended critically on how often the participants intervened. Superstitious people intervened more frequently and gave higher causal ratings, but once the propensity to intervene had been statistically controlled for, there was no further relationship between superstition and causal ratings.

At first glance this finding may appear inconsistent with the present results. However, there is an important difference between Blanco et al.'s (2015) study and the present experiment that may account for this apparent discrepancy. In Blanco et al.'s task, but not in the present task, people were free to intervene as often as they liked. Under these conditions, the superstitious people chose to intervene more frequently, and they had correspondingly less opportunity to observe whether non-intervention was efficacious too (whether the patient improved without medication). As noted above, Blanco et al. used partial correlations to investigate whether differences in illusory control (revealed by causal 
ratings) were independent of superstitious people's greater propensity to intervene, and found no evidence for this pattern. Yet it is possible that the propensity to intervene (an action), and the degree to which people interpret a zero-contingency relationship as causal (an interpretation), are both facets of superstitious reasoning, and therefore may themselves be correlated. If this were so, then Blanco et al.'s (2015) use of partial correlations to control for frequency of intervening would render their analysis insensitive to detect any differences in interpretation between high and low superstitious people: in effect, by controlling for one variable, this approach also reduces any possible influence of the second. This leaves open the possibility that (1) frequency of intervening and (2) a bias in interpretation are both components of superstition, and they tend to go hand-in-hand.

The present study importantly advances our understanding of superstitious beliefs by providing a useful complement to the study by Blanco et al. (2015). In the current task, explicit instructions were used to encourage a similar proportion of interventions (buttonpresses) across individuals. This allowed for greater power to investigate any differences between individuals in their causal interpretation of a (largely) fixed set of observations (at the expense of the ability to investigate differences in participants' natural propensity to intervene). In other words, our procedure allowed us to study whether superstition is associated with the extent to which people perceive illusory control above and beyond any effect it has on their propensity to intervene. Under these circumstances, superstition predicted both the likelihood and magnitude of a causal illusion.

Overall, then, the data suggest that superstition may be associated with two components that contribute to a tendency to perceive illusory causation: a bias in action (intervene too frequently) and also a bias in interpretation (overestimate causation). These two components may both be related to a more general bias to overvalue instances in which 
a cause and effect co-occur (conjunctive events) and undervalue instances when only a single constituent event occurred (disjunctive events). Specifically, Blanco et al.'s (2015) finding demonstrates that highly superstitious people adopt a particular hypothesis-testing strategy (intervene frequently) that is likely to generate many conjunctive events ${ }^{2}$, and relatively few disjunctive events (cause absent/effect present, or cause present/effect absent trials). The present study goes further in suggesting that even when this biasing influence of frequent intervention is absent, superstitious people also differ from non-superstitious people in their interpretation of the experienced cause/effect contingencies, such that they perceive more causation. This could be due to an over-weighting of conjunctive events relative to disjunctive events in the internal causal estimation process itself. In summary, then, the existing evidence suggests that superstitious people may be more likely to test causation in a manner that generates conjunctive events, and are also more influenced by the presence of these events when they occur. Such a bias could well lead to spurious causal beliefs, in a manner broadly consistent with the mechanism for superstitious learning proposed by Skinner (1948).

Notably, this interpretation is also consistent with earlier cognitive investigations of superstition. For example, Rogers, Davis \& Fisk (2009) noted that people who hold paranormal beliefs (e.g., telepathy) were more likely to demonstrate a conjunction error than those who did not. A conjunction error refers to the erroneous belief that the conjunction of two events, $P(\mathrm{~A} \cap \mathrm{B})$, is more likely than is either constituent event, $P(\mathrm{~A})$ or $P(\mathrm{~B})$. The classic example of this error is the "Linda" problem, whereby after receiving some background

\footnotetext{
${ }^{2}$ On the assumption that the effect is relatively likely to occur on each trial - which was the case in Blanco et al.'s (2015) study, where the effect occurred on $75 \%$ of trials regardless of whether participants chose to intervene.
} 
information about a fictional woman (Linda), people often assert that it is more likely that Linda is both a feminist and a bank teller, than it is that she is a bank teller (Tversky \& Kahneman, 1983). This is a logical impossibility, and often interpreted as evidence of the representativeness bias. Yet this pattern of responding could also occur if people overweight conjunctive events during reasoning, as proposed here.

Disruptions in conjunctive reasoning are consistent with broader cognitive biases observed in people with high levels of paranormal beliefs. For example, Brugger et al (1990; see also Mohr, Kourtakis \& Kuhn, 2015) studied perceptions of randomness in low- and high-superstitious individuals (assessed using the AS-GS). They had participants inspect or generate a series of random numbers. People high in superstition-like beliefs tended to avoid patterns that included repetitions of the same number, relative to those with lower superstition, even though some degree of repetition should occur by chance. One interpretation of this finding is that superstitious people systematically underestimate the likelihood of a coincidence (the co-occurrence of two monitored events) occurring, and are therefore more influenced by such co-occurrences when they do occur (even if by chance). Of course, merely observing a coincidence is insufficient to support a superstitious belief. Instead, superstition requires the interpretive binding of the events involved in the coincidence as due to some causal relationship. The present study speaks to this link, with those high in superstition being more likely to attribute causation when coincidences were detected. However, the present study does not identify how complex causal beliefs are constructed (how does seeing a black cat reduce the chance of the bus arriving on time?). Gianotti, Mohr, Pizzagalli, Lehmann \& Brugger (2008) suggested that loosened associations or creativity play an important role in this interpretive process. They showed that when faced with two seemingly unrelated words, people with paranormal beliefs offered more creative 
and idiosyncratic associations than did those with fewer paranormal beliefs. With respect to how such cognitive biases may be substantiated by the brain, initial evidence has been provided by Mohr and colleagues. For example, Mohr et al (2005) found disruption in hemispheric lateralization that is related to paranormal beliefs (or magical ideation), but which can be altered by manipulating dopamine bioavailability (see also Krummenacher, Mohr, Haker \& Brugger, 2010; Mohr, Landis, Sandor, Fathi \& Brugger, 2004).

\section{Evaluation of the Superstitious Beliefs Questionnaire (SBQ)}

The novel SBQ scale used to assess superstitious beliefs in the present study possessed some desirable psychometric properties. It yielded a wide range of scores even with an undergraduate student sample (which might otherwise be expected to be relatively homogeneous), and these scores were approximately normally distributed. It also showed good internal consistency, and high test-retest reliability measured over two weeks in the online sample of Experiment 2. This latter study also demonstrated that the SBQ had good convergent validity with two other measures of superstitious beliefs that have been commonly used in previous studies (PBS and AS-GS). With respect to factor structure, an exploratory factor analysis found a single dominant component (a 'general superstition' factor), which all items loaded most strongly on. Perhaps most importantly, the current study shows that the SBQ has predictive validity. That is, scores on this scale predicted which participants would be most likely to perceive an illusory causal relationship between an (unrelated) action and outcome in Experiment 1. Taken together, these findings suggest that the SBQ provides a useful tool for measuring the strength of modern day superstitious beliefs.

SBQ scores did not significantly correlate with symptoms of depression, anxiety or 
stress in Experiment 1, and so do not appear to be driven by people's current mood state. However, perceived lack of control of the environment (an external locus of control) significantly predicted high levels of superstition. This relationship is partly methodological, as there is overlap in the items assessed by the IE-LOC and the SBQ, including belief in the causal influence of luck or fate. In any case, this relationship has been documented and discussed elsewhere, albeit using different measures of the same constructs (Tobacyk, Nagot \& Miller, 1988; Groth-Narnat \& Pegden, 1998). Importantly, the predictive validity of SBQ scores with regard to causal judgments highlighted above was not simply a consequence of its overlap with the existing IE-LOC measure. SBQ predicted causal judgments even when IELOC scores were controlled for, which suggests that the predictive validity of the SBQ results is a specific property of this questionnaire, rather than the other instruments used here.

\section{Conclusion}

The present data build on previous investigations of superstition by demonstrating a direct relationship between a person's level of self-reported superstitious belief and both the likelihood of experiencing an illusion of control, and its perceived magnitude. Contrary to prior investigations, this relationship could not be accounted for by differences amongst individuals in their propensity to intervene (button-press) or any differences in mood or locus of control. Moreover, the study used a novel measure of superstitious beliefs, which was constructed in order to more closely approximate the kinds of implausible causal relationships many people endorse (and utilize) in daily life. The results suggest that high levels of superstitious beliefs may be associated with a general bias in interpretation, with conjunctive events (positive evidence) being overweighted relative to disjunctive events (negative evidence). More broadly, these findings support the idea that studying basic 
cognitive processes can shed light on the aetiology of pervasive thoughts, beliefs and behaviours outside of the laboratory. 


\section{References}

Aarnio, K., \& Lindeman, M. (2005). Paranormal beliefs, education, and thinking styles. Personality and Individual Differences, 39(7), 1227-1236.

Allan, L. G., \& Jenkins, H. M. (1980). The judgment of contingency and the nature of the response alternatives. Canadian Journal of Psychology, 34(1), 1-11.

Allan, L. G., Siegel, S., \& Hannah, S. (2007). The sad truth about depressive realism. The Quarterly Journal of Experimental Psychology, 60(3), 482-495.

Alloy, L. B., \& Abramson, L. Y. (1979). Judgements of contingency in depressed and nondepressed students: Sadder but wiser. Journal of Experimental Psychology: General, 108, 441-485.

Alloy, L. B., \& Abramson, L. Y. (1982). Learned helplessness, depression, and the illusion of control. Journal of Personality and Social Psychology, 42(6), 1114.

Alloy, L. B., Abramson, L. Y., \& Kossman, D. A. (1985). The judgment of predictability in depressed and nondepressed college students. In F. R. Brush \& J. B. Overmier (Eds.), Affect, conditioning, and cognition: Essays on the determinants of behavior (pp. 229246). Hillsdale, NJ: Erlbaum.

Alloy, L. B., \& Clements, C. M. (1992). Illusion of control: Invulnerability to negative affect and depressive symptoms after laboratory and natural stressors. Journal of Abnormal Psychology, 101, 234-245. doi:10.1037/0021-843X.101.2.234.

Baker, A.G., Murphy, R.A.\& Vallée-Tourangeau, F. (1996). Associative and normative models of causal induction: Reacting to versus understanding cause. In D.R.Shanks, K.J.Holyoak \& D.L.Medin (Eds.), The Psychology of Learning and Motivation, Vol. 34, (pp. 1-45) San Diego, CA: Academic Press.

Bartlett, M. S. (1954). A note on the multiplying factors for various $\chi 2$ approximations. Journal of the Royal Statistical Society B, 296-298.

Bansal, S. B., Dixit, S., Waskel, B., Mahore, R. K., Mishra, S., \& Rokde, R. (2015). An observational study regarding prevalence of superstitious beliefs among patients admitted at a tertiary hospital in Indore. Journal of Evolution of Medical and Dental Sciences, 4(23), 3980-3985.

Beck, J., \& Forstmeier, W. (2007). Superstition and belief as inevitable by-products of an adaptive learning strategy. Human Nature, 18(1), 35-46.

Blackmore, S. \& Troscianko, T. (1985) Belief in the paranormal: probability judgments, illusory control, and the "chance baseline shift." British Journal of Psychology, 76, 459-468.

Blanco, F., Barberia, I., \& Matute, H. (2015). Individuals who believe in the paranormal expose themselves to biased information and develop more causal illusions than nonbelievers in the laboratory. PloS One, 10(7), e0131378.

Brugger P \& Graves RE (1997) Testing vs. Believing Hypotheses: Magical Ideation in the Judgement of Contingencies. Cognitive Neuropsychiatry, 2, 251-272.

Brugger, P., Landis, T., and Regard, M. (1990). A sheep goat effect in repetition avoidance extra-sensory perception as an effect of subjective-probability. British Journal of Psychology, 81, 455-468.

Cattell, R. B. (1966). The scree test for the number of factors. Multivariate Behavioral Research, $1(2), 245-276$.

Chapman, L. J., \& Chapman, J. P. (1987). The search for symptoms predictive of schizophrenia. Schizophrenia Bulletin, 13(3), 497. 
Cheng, P. W. (1997). From covariation to causation: A causal power theory. Psychological Review, 104, 367-405.

Cronbach, L. J. (1951). Coefficient alpha and the internal structure of tests. Psychometrika, 16, 297-334.

Damisch, L., Stoberock, B., \& Mussweiler, T. (2010). Keep your fingers crossed! How superstition improves performance. Psychological Science, 21(7), 1014-1020.

de Leeuw, J.R. (2015). jsPsych: A JavaScript library for creating behavioral experiments in a web browser. Behavior Research Methods, 47, 1-12.

Einstein, D. A., \& Menzies, R. G. (2004). The presence of magical thinking in obsessive compulsive disorder. Behaviour Research and Therapy, 42(5), 539-549.

French, C. C. (1992). Factors underlying belief in the paranormal: Do sheep and goats think differently. The Psychologist, 5, 295-299.

Galak, J., LeBoeuf, R.A., Nelson, L.D., \& Simmons, J.P. (2012). Correcting the past: Failures to replicate psi. Journal of Personality and Social Psychology, 103, 933-948.

Garrett, H. E., \& Fisher, T. R. (1926). The prevalence of certain popular misconceptions. Journal of Applied Psychology, 10(4), 411.

Gianotti, L. R., Mohr, C., Pizzagalli, D., Lehmann, D., \& Brugger, P. (2001). Associative processing and paranormal belief. Psychiatry and Clinical Neurosciences, 55(6), 595603.

Gregory, C. J. (1975). Changes in superstitious beliefs among college women. Psychological Reports, 37(3), 939-944.

Groth-Marnat, G., \& Pegden, J. A. (1998). Personality correlates of paranormal belief: Locus of control and sensation seeking. Social Behavior and Personality: An International Journal, 26(3), 291-296.

Irwin, H. J. (1993). Belief in the paranormal: A review of the empirical literature. The Journal of the American Society for Psychical Research, 87, 1-38.

JASP Team (2017). JASP (Version 0.8.2) [Computer software].

Jenkins, H. M., \& Ward, W. C. (1965). Judgment of contingency between responses and outcomes. Psychological Monographs, 79, 1-17.

Johns, L. C., \& Van Os, J. (2001). The continuity of psychotic experiences in the general population. Clinical Psychology Review, 21(8), 1125-1141.

Kaiser, H. F., \& Rice, J. (1974). Little jiffy, mark IV. Educational and Psychological Measurement, $34(1), 111-117$.

Keinan, G. (2002). The effects of stress and desire for control on superstitious behavior. Personality and Social Psychology Bulletin, 28, 102-108.

Krummenacher, P., Mohr, C., Haker, H., \& Brugger, P. (2010). Dopamine, paranormal belief, and the detection of meaningful stimuli. Journal of Cognitive Neuroscience, 22(8), 1670-1681.

Langer, E. J. (1975). The illusion of control. Journal of Personality and Social Psychology, 32, 311-328.

Lindeman, M., \& Aarnio, K.(2006). Paranormal beliefs: Their dimensionality and correlates. European Journal of Personality, 20, 585-602.

Lovibond, P. F., \& Lovibond, S. H. (1995). The structure of negative emotional states: Comparison of the Depression Anxiety Stress Scales (DASS) with the Beck Depression and Anxiety Inventories. Behaviour Research and Therapy, 33(3), 335-343.

Maier, S. F., \& Seligman, M. E. (1976). Learned helplessness: Theory and evidence. Journal of Experimental Psychology: General, 105(1), 3. 
Marsman, M., \& Wagenmakers, E. J. (2017). Bayesian benefits with JASP. European Journal of Developmental Psychology, 14(5), 545-555.

Matute, H. (1994). Learned helplessness and superstitious behavior as opposite effects of uncontrollable reinforcement in humans. Learning and Motivation, 25, 216-232.

Matute, H. (1995). Human reactions to uncontrollable outcomes: Further evidence for superstitions rather than helplessness. Quarterly Journal of Experimental Psychology Section $B, 48,142-157$.

Matute, H. (1996). Illusion of control: Detecting response-outcome independence in analytic but not in naturalistic conditions. Psychological Science, 7, 289-293.

Matute, H., Yarritu, I., \& Vadillo, M. A. (2011). Illusions of causality at the heart of pseudoscience. British Journal of Psychology, 102(3), 392-405.

Mohr, C., Koutrakis, N., \& Kuhn, G. (2015). Priming psychic and conjuring abilities of a magic demonstration influences event interpretation and random number generation biases. Frontiers in Psychology, 5, 1542.

Mohr, C., Krummenacher, P., Landis, T., Sandor, P. S., Fathi, M., \& Brugger, P. (2005). Psychometric schizotypy modulates levodopa effects on lateralized lexical decision performance. Journal of Psychiatric Research, 39(3), 241-250.

Mohr, C., Landis, T., Sandor, P. S., Fathi, M., \& Brugger, P. (2004). Nonstereotyped responding in positive schizotypy after a single dose of levodopa. Neuropsychopharmacology, 29(9), 1741.

Msetfi, R. M., Murphy, R. A., \& Simpson, J. (2007). Depressive realism and the effect of intertrial interval on judgements of zero, positive, and negative contingencies. Quarterly Journal of Experimental Psychology, 60, 461-481

Musch, J. \& Ehrenberg, K. (2002) Probability misjudgment, cognitive ability, and belief in the paranormal. British Journal of Psychology, 93, 169-177.

Peters, E. R., Joseph, S. A., \& Garety, P. A. (1999). Measurement of delusional ideation in the normal population: introducing the PDI (Peters et al. Delusions Inventory). Schizophrenia Bulletin, 25(3), 553.

Pronin, E., Wegner, D. M., McCarthy, K., \& Rodriguez, S. (2006). Everyday magical powers: The role of apparent mental causation in the overestimation of personal influence. Journal of Personality and Social Psychology, 91, 218-231.

Rogers, P., Davis, T., \& Fisk, J. (2009). Paranormal belief and susceptibility to the conjunction fallacy. Applied Cognitive Psychology, 23, 524-542.

Rotter, J. B. (1966) Generalized expectancies for internal versus external control of reinforcement. Psychological Monographs: General and Applied, 80(1), 1.

Rotter, J. B. (1975). Some problems and misconceptions related to the construct of internal versus external control of reinforcement. Journal of Consulting and Clinical Psychology, 43(1), 56.

Russell, D., \& Jones, W. H. (1980). When superstition fails: Reactions to disconfirmation of paranormal beliefs. Personality and Social Psychology Bulletin, 6(1), 83-88.

Shanks, D. R. (1985). Continuous monitoring of human contingency judgment across trials. Memory \& Cognition, 13(2), 158-167.

Sica, C., Novara, C., \& Sanavio, E. (2002). Culture and psychopathology: superstition and obsessive-compulsive cognitions and symptoms in a non-clinical Italian sample. Personality and Individual Differences, 32(6), 1001-1012.

Skinner, B. F. (1948). Superstition in the pigeon. Journal of Experimental Psychology, 8, 168172. 
Staddon, J. E. R. (1992). The" superstition" experiment: A reversible figure. Journal of Experimental Psychology: General, 121(3), 270.

Sobal, J., \& Eamons, C. F. (1982). Patterns of belief in religious, psychic, and other paranormal phenomena. Zetetic Scholar, 9, 7-17.

Tobacyk, J. J. (2004). A revised paranormal belief scale. The International Journal of Transpersonal Studies, 23(23), 94-98.

Tobacyk, J. J., Nagot, E., \& Miller, M. (1988). Paranormal beliefs and locus of control: A multidimensional examination. Journal of Personality Assessment, 52(2), 241-246.

Thalbourne, MA, \& Delin, PS (1993). A new instrument for measuring the sheep-goat variable: Its psychometric properties and factor structure. Journal of the Society for Psychical Research, 59, 172-186

Tversky, A. \& Kahneman, D. (1983). Extensional versus intuitive reasoning: The conjunction fallacy in probability judgment. Psychological Review. 90 (4): 293-315

Vadillo, M., Musca, S.C, Blanco, F. \& Matute, H (2010) Contrasting cue-density effects in causal and prediction judgments. Psychonomic Bulletin \& Review, 18(1), 110-115.

Vallée-Tourangeau, F., Hollingsworth, L., \& Murphy, R. A. (1998). "Attentional bias" in correlation judgments? Smedslund (1963) revisited. Scandinavian Journal of Psychology, 39, 221-233.

Van Elk, M. (2013) Paranormal believers are more prone to illusory agency detection than skeptics. Consciousness \& Cognition, 22, 1041-1046.

Wasserman, E. A., Elek, S. M., Chatlosh, D. L., \& Baker, A. G. (1993). Rating causal relations: Role of probability in judgments of response outcome contingency. Journal of Experimental Psychology: Learning, Memory, and Cognition, 19, 174-188.

Watkins, M. W. (2005). Determining parallel analysis criteria. Journal of Modern Applied Statistical Methods, 5(2), 8.

Wetzels, R., \& Wagenmakers, E. J. (2012). A default Bayesian hypothesis test for correlations and partial correlations. Psychonomic Bulletin \& Review, 19(6), 1057-1064.

Wiseman, R., \& Watt, C. (2006). Belief in psychic ability and the misattribution hypothesis: A qualitative review. British Journal of Psychology, 97, 323-338.

Wohl, M. J. A., \& Enzle, M. E. (2009). Illusion of control by proxy: Placing one's fate in the hands of another. British Journal of Social Psychology, 48, 183-200.

Yarritu, I., Matute, H., \& Luque, D. (2015). The dark side of cognitive illusions: When an illusory belief interferes with the acquisition of evidence-based knowledge. British Journal of Psychology, 106(4), 597-608.

Zusne, L., \& Jones, W. H. (1989). Anomalistic psychology: A study of magical thinking (2nd ed.). Hillsdale, NJ: Erlbaum. 
Table 1. Demographic information and summary data from Experiment 1.

\begin{tabular}{|c|c|c|c|c|}
\hline & & \multicolumn{2}{|c|}{ Condition } & \multirow{2}{*}{ Difference } \\
\hline & & Unrewarded & Rewarded & \\
\hline$N$ & & 74 & 79 & \\
\hline Age & $\begin{array}{l}M \\
(S D)\end{array}$ & $\begin{array}{l}19.5 \\
(5.0)\end{array}$ & $\begin{array}{l}18.5 \\
(0.8)\end{array}$ & $p=.11$ \\
\hline$\%$ female & & $70.2 \%$ & $57.0 \%$ & $p=.088$ \\
\hline \multicolumn{5}{|c|}{ Causal judgment task } \\
\hline Experienced $\Delta P$ & $\begin{array}{l}M \\
(S D)\end{array}$ & $\begin{array}{r}0.00 \\
(0.06)\end{array}$ & $\begin{array}{r}0.00 \\
(0.06)\end{array}$ & $p=.77$ \\
\hline$\%$ button-presses & $\begin{array}{l}M \\
(S D)\end{array}$ & $\begin{array}{r}53.5 \% \\
(12.7 \%)\end{array}$ & $\begin{array}{r}55.3 \% \\
(12.3 \%)\end{array}$ & $p=.37$ \\
\hline Causal judgment & $\begin{array}{l}M \\
(S D)\end{array}$ & $\begin{array}{r}30.1 \\
(24.3)\end{array}$ & $\begin{array}{r}40.3 \\
(25.8)\end{array}$ & $p=.013$ \\
\hline \multicolumn{5}{|l|}{ Questionnaires } \\
\hline SBQ & $\begin{array}{l}M \\
\text { (SD) }\end{array}$ & $\begin{array}{r}48.2 \\
(15.7)\end{array}$ & $\begin{array}{r}45.7 \\
(15.5)\end{array}$ & $p=.33$ \\
\hline DASS depression & $\begin{array}{l}M \\
(S D)\end{array}$ & $\begin{array}{r}3.92 \\
(3.28)\end{array}$ & $\begin{array}{r}3.00 \\
(3.49)\end{array}$ & $p=.096$ \\
\hline DASS anxiety & $\begin{array}{l}M \\
(S D)\end{array}$ & $\begin{array}{r}3.43 \\
(3.25)\end{array}$ & $\begin{array}{r}3.30 \\
(2.92)\end{array}$ & $p=.80$ \\
\hline DASS stress & $\begin{array}{l}M \\
(S D)\end{array}$ & $\begin{array}{r}5.58 \\
(3.25)\end{array}$ & $\begin{array}{r}4.70 \\
(3.34)\end{array}$ & $p=.10$ \\
\hline IE-LOC & $\begin{array}{l}M \\
(S D)\end{array}$ & $\begin{array}{l}11.57 \\
(2.61)\end{array}$ & $\begin{array}{l}12.41 \\
(2.71)\end{array}$ & $p=.054$ \\
\hline
\end{tabular}

Note: Demographic information and summary data for participants in the Unrewarded and Rewarded conditions. The right-hand column (labelled "Difference") indicates the significance level $(p)$ for an independent samples t-test comparing the scores of the two conditions (with the exception of ' $\%$ female', where the $p$-value relates to a $\chi^{2}$ test).

Experienced $\Delta P=$ contingency between button-pressing and light illuminating, calculated via Equation 1; \% button-presses = percentage of trials on which participants chose to press the button; Causal judgment = rating of the strength of the causal relationship between buttonpressing and light illuminating (on a scale from 0 to 100); SBQ = Superstitious Beliefs Questionnaire; DASS = Depression, Anxiety and Stress Scale (21-item); IE-LOC = Internal/External Locus of Control scale. 
Table 2. Correlation matrix for Experiment 1.

\begin{tabular}{lccccc}
\hline & $\begin{array}{c}\text { Causal } \\
\text { judgment }\end{array}$ & SBQ & $\begin{array}{c}\text { DASS } \\
\text { depr }\end{array}$ & $\begin{array}{r}\text { DASS } \\
\text { anx }\end{array}$ & $\begin{array}{c}\text { DASS } \\
\text { stress }\end{array}$ \\
\hline SBQ & $.22^{* *}$ & & & & \\
DASS depr & -.09 & .08 & & & \\
DASS anx & .03 & .13 & $.48^{* * *}$ & & \\
DASS stress & -.08 & .09 & $.61^{* * *}$ & $.61^{* * *}$ & \\
IE-LOC & -.10 & $-.25^{* *}$ & $-.23^{* *}$ & -.05 & -.13 \\
\hline
\end{tabular}

Note: Table shows Pearson correlations $(r)$ of key variables (calculated across all participants). ${ }^{* *} p<.01,{ }^{* *} p<.001$. Causal judgment $=$ rating of the strength of the causal relationship between button-pressing and light illuminating (on a scale from 0 to 100); SBQ = Superstitious Beliefs Questionnaire; DASS depr = depression subscale of Depression, Anxiety and Stress Scale (DASS); DASS anx = anxiety subscale of DASS; DASS stress = stress subscale of DASS; IE-LOC = Internal/External Locus of Control scale. 
Table 3. Demographic information and summary data from Experiment 2 .

\begin{tabular}{llrr}
\hline & & Session 1 & Session 2 \\
\hline$N$ & & 253 & 199 \\
Age & M & 35.5 & 36.3 \\
& $(\mathrm{SD})$ & $(10.8)$ & $(11.1)$ \\
\% female & & $46.0 \%$ & $48.7 \%$ \\
Questionnaires & & & \\
SBQ & $\mathrm{M}$ & 36.2 & 34.5 \\
& $(\mathrm{SD})$ & $(15.7)$ & $(16.1)$ \\
PBS & $\mathrm{M}$ & 70.6 & 68.6 \\
& $(\mathrm{SD})$ & $(32.0)$ & $(31.5)$ \\
AS-GS & $\mathrm{M}$ & 9.5 & 8.2 \\
& $(\mathrm{SD})$ & $(8.7)$ & $(8.2)$ \\
\hline
\end{tabular}

Note: SBQ = Superstitious Beliefs Questionnaire; PBS = Revised Paranormal Beliefs Scale; ASGS = Australian Sheep-Goat Scale. 


\section{Figure Captions}

Figure 1. (A) On each trial of the causal judgment task of Experiment 1, participants decided whether or not to press a button (during a 3s interval). They were then shown whether or not the lightbulb illuminated. (B) Procedure for scheduling trial outcomes in Experiment 1; see text for details.

Figure 2. (A) A histogram of the number of respondents in Experiment 1 whose scores on the Superstitious Beliefs Questionnaire (SBQ) fell within each 10 point bin. The maximum possible score is 100 , but the highest score for any participant was 85 . (B) A scatterplot of participants' causal ratings regarding the strength of the relationship between buttonpressing and illumination of the light, against SBQ scores. Data are shown separately for rewarded and unrewarded conditions; lines show lines of best fit. (C) The distribution of SBQ scores for participants who gave a causal rating of 10 or higher (i.e., those who showed evidence of a causal illusion, labelled "Incorrect"), and those who gave a rating lower than 10 (and hence showed little evidence of a causal illusion, labelled "Correct"). Data are collapsed across rewarded and unrewarded conditions. The horizontal line indicates the mean SBQ score of each group, and error bars show standard error of the mean. 

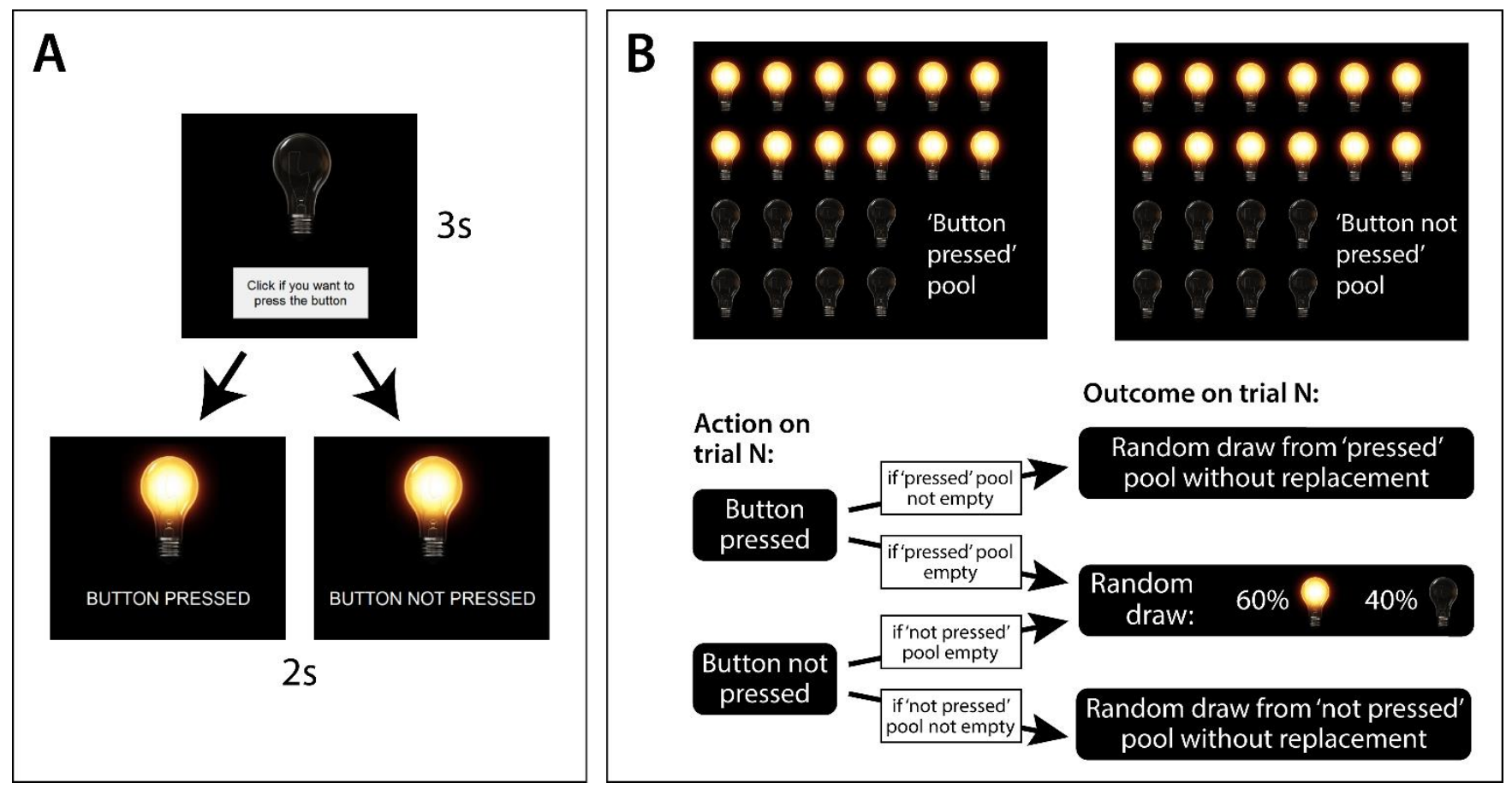

Figure 1 
A

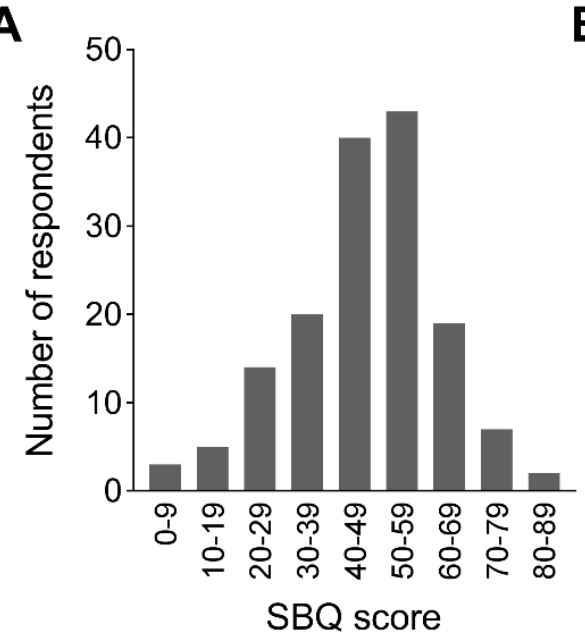

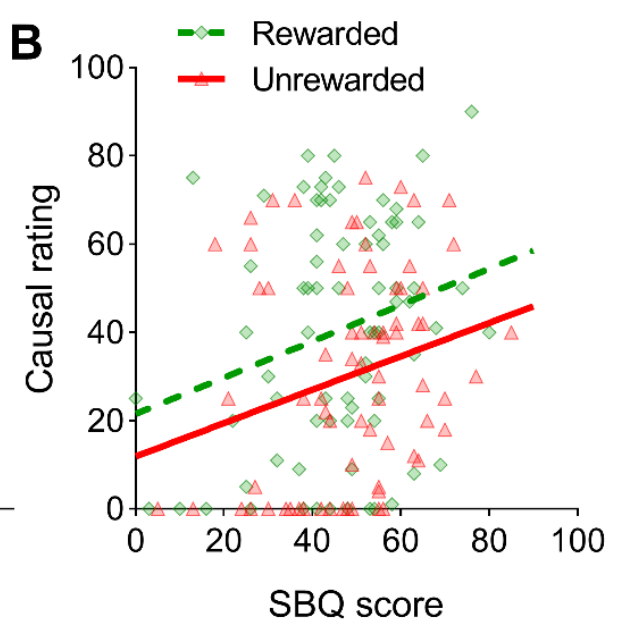

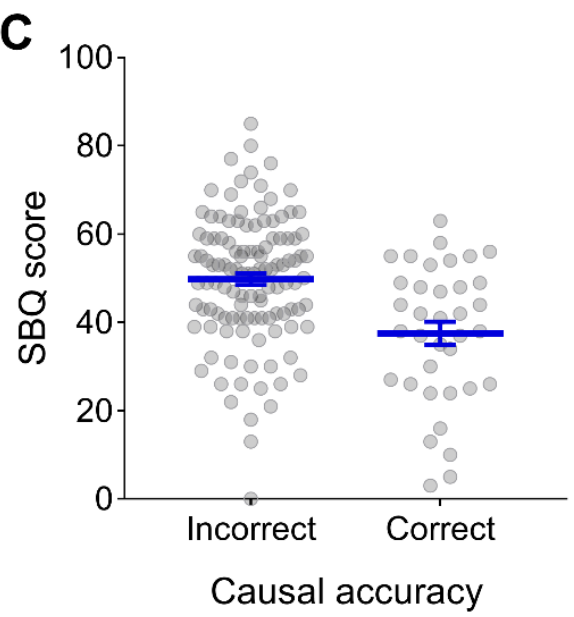

Figure 2 


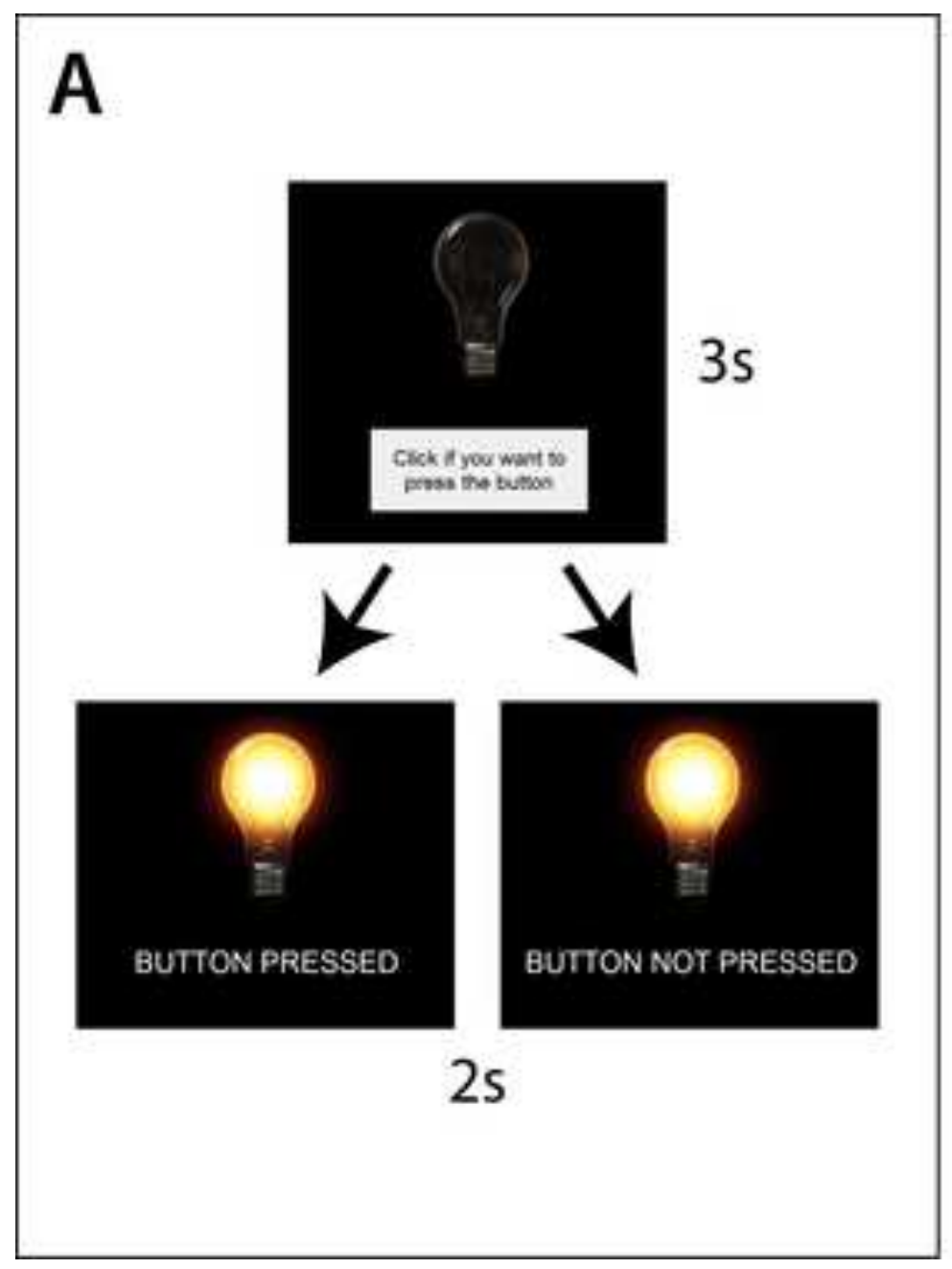

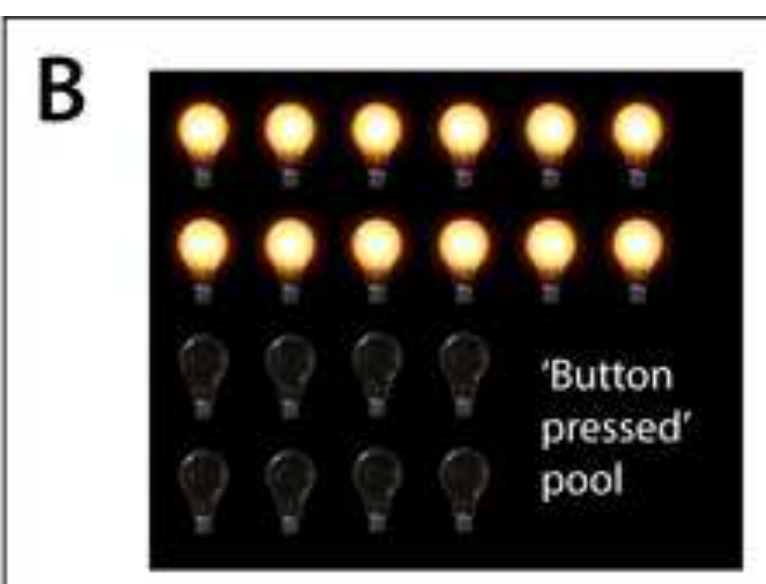
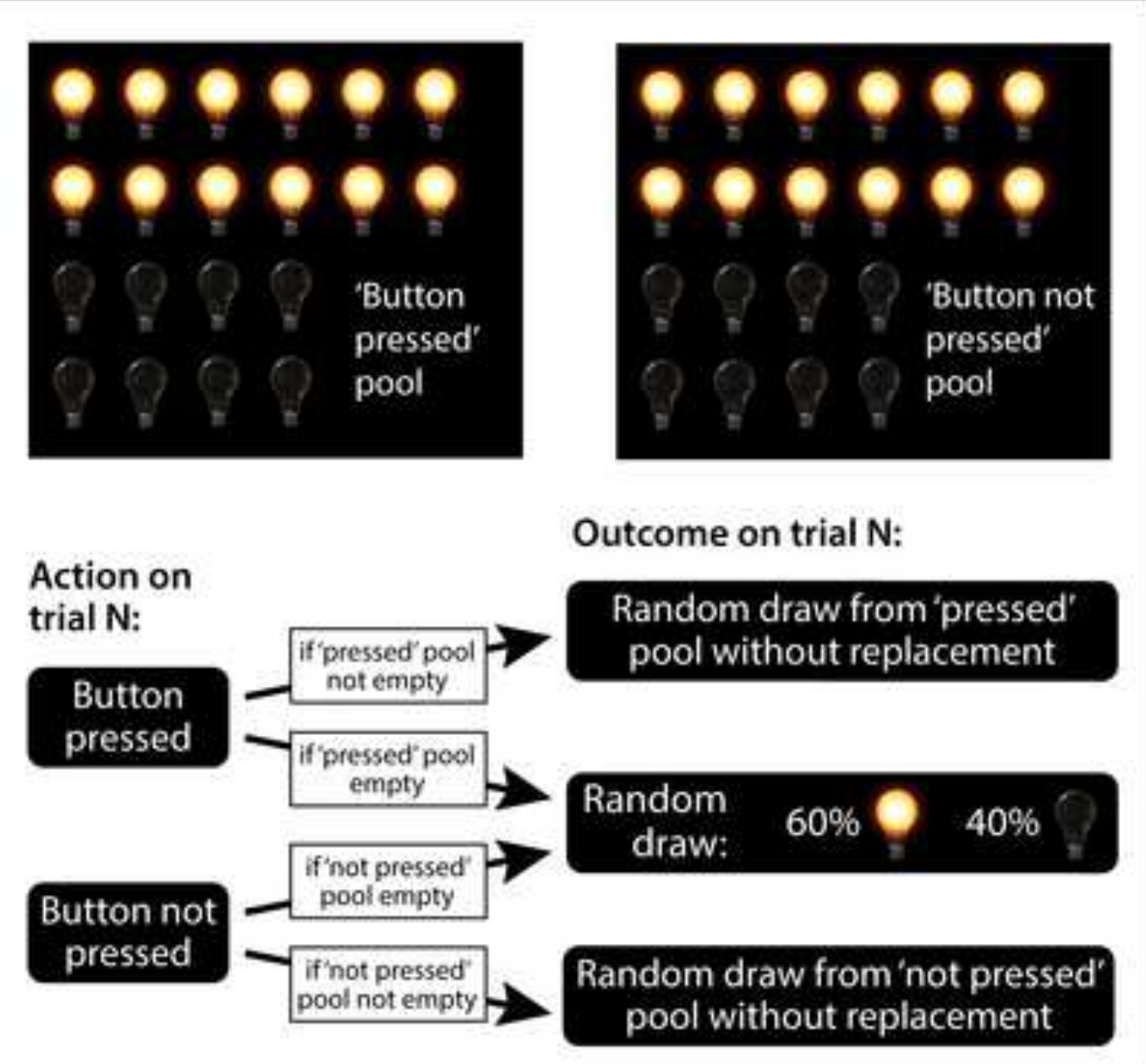

\section{Outcome on trial N:}



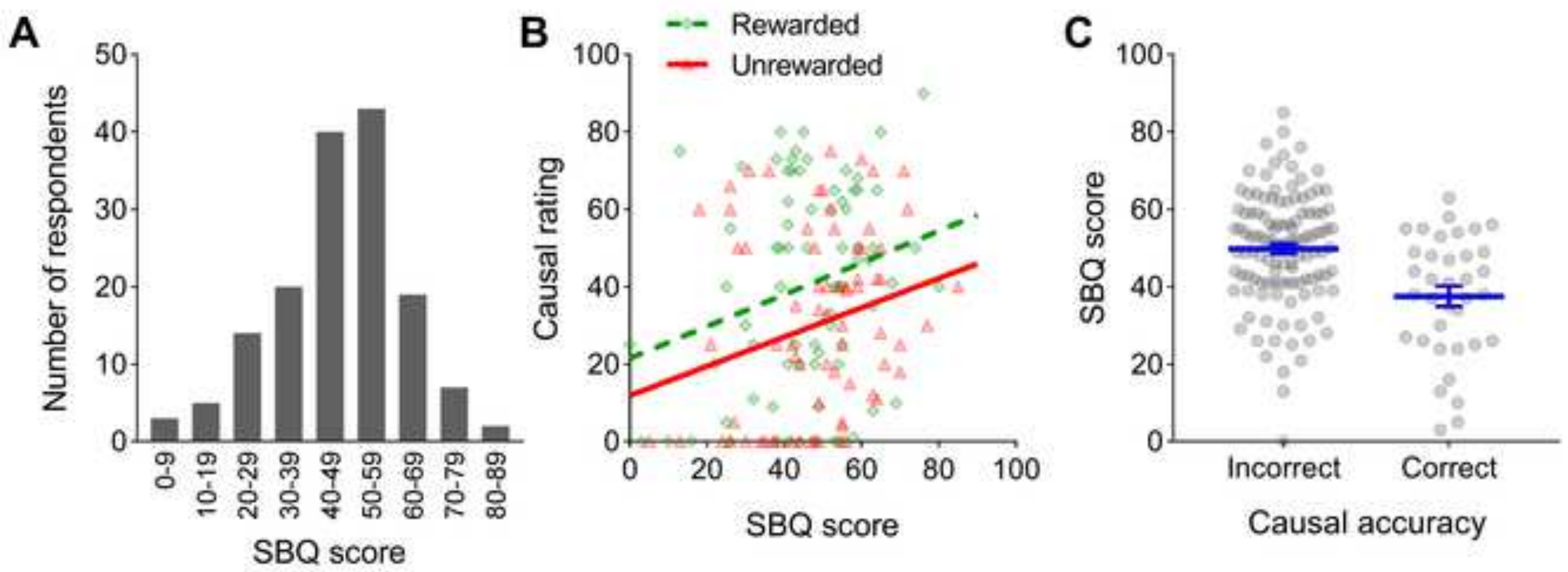


\section{Appendix A: Instructions for causal judgment task}

Instructions for participants in the unrewarded conditions were as below. The passage shown in italics was displayed in 28-point yellow font; all other instructions were shown in 20-point white font (on a black background). These instructions were displayed on-screen; the experimenter read them to the participant, and ensured that the participant understood them.

"In this part of the experiment we are interested in how you judge the relationships between events. Imagine that you are a scientist, and that the apparatus for your latest experiment includes a light bulb wired up to a light switch button. Unfortunately the power supply for the light is rather old and unreliable.

It is very important for your experiment that you feel that you can control when the light is switched on or remains off. Therefore you decide to test the apparatus to assess how much control you have over the light switching on.

On each trial you will see the light bulb on the screen. There will be a short delay and then the switch button will appear too. While the button is on-screen you will be able to click on it and see whether the light switches on or remains off. If the light switches on, it will stay on for 2 seconds before switching off. In the test there will be many opportunities to press the button and see what happens.

In order to judge how much control your button pressing has over whether the 
light comes on, you need to know what happens when you press the button. IT IS ALSO VERY IMPORTANT that you know what happens when you do not press the button. So, on about half of the opportunities, you should sit back and see what happens when you don't press the button.

Later, you will be asked to make a judgement about how much control pressing the button had over whether the light came on.

TOTAL CONTROL means that whether the light switches on is completely determined by your choice of response - either pressing or not pressing the button.

NO CONTROL means that pressing the button has no influence at all on whether the light switches on or not.

PARTIAL CONTROL means that pressing or not pressing the button does influence whether the light switches on, but not completely. In other words, whether you press or don't press the button matters to some extent, but not totally."

Instructions for participants in the rewarded condition were similar, except for the following passage that was inserted immediately after the section in italics:

"How often the light turns on will determine how many points you earn. On each trial on which the light illuminates, you will earn 10 points. On each trial on which the light DOES NOT illuminate, you will not earn any points.

So the more times the light illuminates, the more points you will earn during the 
experiment. The four participants who earn the most points during this experiment will each win a double movie voucher."

Instructions prior to the causal judgment test phase for all participants were as follows:

"You are now asked to make a judgement about how much control pressing the button had over whether the light came on. You will make this judgment using the slider below.

If you think that pressing the button had total control over the light coming on, you should position the slider at the 'Total control' end.

If you think that pressing the button had absolutely no control over the light coming on, you should position the slider at the 'No control' end.

You may think that pressing the button had partial, but not total, control over the light coming on. In this case, you should position the slider accordingly. Putting it nearer to the 'Total control' end means MORE control, while putting it nearer to the 'No control' end means LESS control. 


\section{Appendix B: Superstition Beliefs Questionnaire}

\section{Instructions}

In a recent article in the Journal of Personality and Social Psychology, the psychologist Daryl Bem from Cornell University provided evidence supporting the existence of "psi phenomena". These are phenomena such as telepathy and precognition (having information about future events) that involve processes of energy or information transfer that are currently unexplained in terms of known physical or biological systems.

Bem's work has encouraged researchers to re-examine the evidence for a number of other phenomena that are not easily explained by our current scientific understanding. As a first step, we would like to establish what people currently think about some of these matters.

You will be shown a series of statements, and will be asked to rate how strongly you agree or disagree with each. It is VERY IMPORTANT that you answer as honestly as you can.

\section{Statements}

1. Knowing a person's star-sign can give extra insight into their personality characteristics.

2. Reading horoscopes can help people to anticipate what will happen in the future.

3. The alignment of stars and planets when you are born can influence your personality or your destiny.

4. Sometimes dreams can give us signs and guidance about current or future events in our lives, or the lives of the people around us.

5. The power of our thoughts can sometimes influence the physical world (e.g. thinking about a person might cause them to telephone us, or thinking positive thoughts about a person might cause good things to happen to them). 
6. I would be uncomfortable with taking long trips on a Black Friday (a Friday that falls on the 13th of any month).

7. There are things that we can do to improve our luck (e.g., carrying a lucky charm or choosing our lucky number in a random draw).

8. 'Alternative' therapies (such as homeopathic remedies, aromatherapy, reflexology, chiropractic manipulation, or therapy based on the body's energy fields) can be an effective way of treating illnesses and ailments.

9. Wishing or praying for something can make it more likely to happen.

10. If I passed a ladder I would walk around it rather than underneath it.

11. Certain actions can cause good luck, or prevent bad luck (e.g., knocking on wood, or throwing salt over your shoulder).

12. It is possible to gain information about a person's personality by analysing their handwriting.

13. I am interested in learning more about paranormal activity or psychic phenomena.

14. Recruiting people with psychic abilities can help police and detectives solve crime mysteries more effectively.

15. I believe in soul mates: that is, that there is someone in the world that we are destined to be with.

16. What happens to people is determined by fate.

17. I believe there is more to the workings of the universe than science can explain.

18. I believe in the existence of a higher being (such as a Christian God, Allah, Shiva, Waheguru, or Satan).

19. Prophecies can hold much information about what will happen in the future.

20. I believe that things like palm-reading, fortune-telling or séances are more than forms of entertainment - they can offer us guidance by telling us things that we do not already 
know.

21. I find myself to be more superstitious than most people I know.

22. When making important life decisions I am more likely to call on a 'Higher Self' intuition than logic.

23. Through visualisation, we can attract desired people, events and opportunities into our lives.

24. I believe that everything happens for a reason.

25. Karma is a powerful source for both good and bad events in our lives. 